\title{
Endovascular treatment of ruptured tiny aneurysms
}

\author{
Joon Hyuk Kim, Chang Hwa Choi, Jae II Lee, Tae Hong Lee, Jun Kyeung Ko \\ Department of Neurosurgery, Diagnostic Radiology, Medical Research Institute, Pusan National University Hospital, \\ Busan, Korea
}

\begin{abstract}
Objective : Endovascular coiling of ruptured tiny aneurysms (RTAs) in the brain has been known to be technically challenging owing to the higher rate of adverse events, such as thromboembolism and intraoperative rupture. The aim of this study was to report our ex-periences of endovascular treatment of RTAs (size, $\leq 3 \mathrm{~mm}$ ).

Methods : From January 2006 to December 2017, 35 RTAs in 35 patients were treated at our institution with an endosaccular coiling. Procedural data and clinical and angiographic results were retrospectively reviewed.
\end{abstract}

Results : The mean size of the RTAs was $2.53 \mathrm{~mm}$ (SD: 0.38). The neck remodeling technique was applied to 14 aneurysms, including stent-assisted coiling $(n=7)$ and balloon-assisted coiling $(n=7)$. Procedure-related complications included intraprocedural rupture $(n=2)$, thromboembolic event $(n=1)$, and early rebleeding $(n=2)$, which needed recoiling. Regarding immediate angiographic control, complete occlusion was achieved in 25 aneurysms (71.4\%), small neck remnant in 5 (14.3\%), and definite remnant in $5(14.3 \%)$. At the end of follow-up, 31 of the 35 patients $(88.6 \%)$ were able to function independently. Twenty-two of the 35 patients underwent follow-up conventional angiography (mean, 468 days). Stable occlusion was achieved in 20 of the 22 patients (90.9\%), minor recanalization in $1(4.5 \%)$, and major recanalization, which required recoiling, in $1(4.5 \%)$.

Conclusion : Our experiences demonstrate that endovascular treatment for RTAs is both feasible and effective. However, periprocedural rebleedings were found to occur more often (11.4\%) than what is generally suspected.

Keywords Endovascular coiling, Cerebral aneurysm, Tiny aneurysm

\author{
J Cerebrovasc Endovasc Neurosurg. \\ 2019 June;21(2):67-76 \\ Received : 12 June 2019 \\ Revised : 18 June 2019 \\ Accepted : 20 June 2019
}

\author{
Correspondence to Jun Kyeung Ko \\ Department of Neurosurgery, Pusan National \\ University Hospital, 179 Gudeok-Ro, Seo-Gu, \\ Busan, 49241, Republic of Korea \\ Tel : +82-51-240-7937 \\ Fax : +82-51-244-0282 \\ E-mail : redcheek09@naver.com \\ ORCID : http://orcid.org/0000-0002-5652-7659
}

This is an Open Access article distributed under the terms of the Creative Commons Attribution NonCommercial License (http://creativecommons.org/licenses/by-nc/3.0) which permits unrestricted noncommercial use, distribution, and reproduction in any medium, provided the original work is properly cited.

\section{INTRODUCTION}

It is generally considered difficult and risky to treat a ruptured tiny aneurysm (RTA) via the use of coil embolization. ${ }^{1338) 14418)}$ The main issues are related to the following factors: development of frequently broad-based aneurysms with a shallow dome and complex shape, difficulty in maintaining microcatheter stability, difficulty in achieving complete coil packing, and higher risk of intraprocedural rupture (IPR) and early rebleeding (ERB). ${ }^{2022)}$ However, recent advances in endovascular techniques and devices have led to the rapid evolution of coil embolization of an intracranial aneurysm, which may allow for safer 
coil embolization of RTAs. ${ }^{711)}$ Relatively few studies have been performed on endovascular treatment (EVT) of RTAs, and the studies performed involved relatively small numbers of patients. Accordingly, it is evident that the effectiveness and safety of EVT of RTAs have not been well defined. Herein, we present our experience in endovascularly treating 35 patients for an RTA (size, $\leq 3 \mathrm{~mm}$ ) and describe their clinical and radiologic outcomes.

\section{MATERIALS AND METHODS}

We retrospectively analyzed the angiographic and clinical records of all patients who underwent EVT for RTAs at our institution from April 2006 to December 2017. Only patients with aneurysms sized $\leq$ $3 \mathrm{~mm}$ were included in the study. The sizes of their aneurysms and parent arteries were measured automatically and manually on two-dimensional digital subtraction angiography working views. Dissecting or bleb aneurysms, aneurysms associated with a brain arteriovenous malformation, and traumatic or mycotic aneurysms were excluded. All procedures were performed by three experienced neurointerventionist (J.K.K., J.I.L., and T.H.L.). In most cases, the patients were eligible for both treatment modalities. Factors, including patient characteristics, aneurysm features, and operator's preferences, were taken into account in the decision-making process. The patients with posterior circulation aneurysms were primarily offered endovascular therapy. Conversely, the patients with a large intraparenchymal hematoma underwent open surgery for aneurysm clipping and simultaneous clot evacuation and decompression. Elderly patients with multiple comorbidities or poor neurological grades were often preferentially offered an endovascular procedure. Aneurysms with an unfavorable neck-to-dome ratio were either clipped or coiled using stent or balloon assistance. Owing to the retrospective nature of the present study, the need for obtaining informed consent was waived by our Institutional
Review Board

\section{Patient population and aneurysm morphologies}

The demographic data of the patients and characteristics of the aneurysms are provided in Table 1. Thirty-five RTAs in 35 patients were treated endovascularly, and there were 8 men and 27 women with a mean age of 56 years (SD, 14.4; range, 29-81). The aneurysm and neck sizes ranged from 1.7 to $3.0 \mathrm{~mm}$ (mean, $2.53 \mathrm{~mm}$ ) and from 1 to $2.6 \mathrm{~mm}$ (mean, 1.73 $\mathrm{mm})$, respectively. The average aspect ratio of RTAs was 1.51 (SD: 0.34). Of the 35 RTAs, 14 were located at the anterior communicating artery; 6 at the anterior choroidal artery; 3 each at the paraclinoid internal carotid artery, proximal anterior cerebral artery, and distal anterior cerebral artery; 2 each at the distal middle cerebral artery and posterior communicating artery; and 1 each at the bifurcation of the middle cerebral artery and superior cerebellar artery. Four patients had at least one additional aneurysm. All pa-

Table 1. Patient demographic data and characteristics of the aneurysms

\begin{tabular}{|c|c|}
\hline $\begin{array}{l}\text { Number of patients } \\
\text { Number of coiled RTAs }\end{array}$ & $\begin{array}{l}35 \\
35\end{array}$ \\
\hline $\begin{array}{l}\text { Gender, n (\%) } \\
\text { Male } \\
\text { Female }\end{array}$ & $\begin{aligned} 8 & (22.9) \\
27 & (77.1)\end{aligned}$ \\
\hline $\begin{array}{l}\text { Hunt Hess grade, } \mathrm{n}(\%) \\
\text { I } \\
\text { II } \\
\text { III } \\
\text { IV } \\
\text { V }\end{array}$ & $\begin{aligned} 3 & (8.6) \\
12 & (34.3) \\
17 & (48.6) \\
2 & (5.7) \\
1 & (2.9)\end{aligned}$ \\
\hline $\begin{array}{l}\text { Fisher grade, n (\%) } \\
\quad 1 \\
2 \\
3 \\
4\end{array}$ & $\begin{aligned} 3 & (8.6) \\
10 & (28.6) \\
22 & (62.9) \\
& 0\end{aligned}$ \\
\hline $\begin{array}{l}\text { Location of aneurysm, } \mathbf{n}(\%) \\
\text { Anterior communicating artery } \\
\text { Anterior choroidal artery } \\
\text { Paraclinoid internal carotid artery } \\
\text { Proximal anterior cerebral artery } \\
\text { Distal anterior cerebral artery } \\
\text { Distal middle cerebral artery } \\
\text { Posterior communicating artery } \\
\text { Bifurcation of middle cerebral artery } \\
\text { Superior cerebellar artery }\end{array}$ & $\begin{aligned} 14 & (40) \\
6 & (17.1) \\
3 & (8.6) \\
3 & (8.6) \\
3 & (8.6) \\
2 & (5.7) \\
2 & (5.7) \\
1 & (2.9) \\
1 & (2.9)\end{aligned}$ \\
\hline $\begin{array}{l}\text { Size of aneurysm } \\
\text { Maximum diameter of aneurysm }(\mathrm{mm}) \\
\text { Aneurysm neck size }(\mathrm{mm})\end{array}$ & $\begin{array}{l}2.53 \pm 0.38(1.7-3.0) \\
1.73 \pm 0.44(1-2.5)\end{array}$ \\
\hline
\end{tabular}


tients were clinically assessed at admission using the Hunt and Hess grades: 3 patients (8.6\%), grade I; 12 patients, grade II (34.3\%); 17 patients, grade III (48.6\%); 2 patients, grade IV (5.7\%); and 1 patient, grade V (2.9\%). Further, the Fisher grade in all patients was assessed: 3 patients, grade 1 (8.6\%); 10 patients, grade 2 (28.6\%); and 22 patients, grade 3 $(62.9 \%)$.

\section{Endovascular procedure}

In general, EVT was performed as soon as possible after subarachnoid hemorrhage, regardless of clinical condition. No antiplatelet premedication was prescribed in any patients because of the risk of rebleeding. Coiling of the aneurysms was performed under local anesthesia, and intravenous bolus injection of standard heparin was not performed during the procedure. However, drip infusion of heparin was conducted employing catheter pressure infusion systems with continuous infusion of $1000 \mathrm{U}$ of heparin per $1000 \mathrm{~mL}$ of saline. The aim of the coiling procedure was to obtain a packing of the aneurysm as attenuated as possible. Various technical measures and precautions were taken to overcome specific problems. Remodeling techniques using a balloon or stent or multiple catheters were unavailable for the aneurysms treated during the early part of our series. However, we have recently favored these remodeling techniques to achieve higher postoperative occlusion rates. In the case of intraprocedural thromboembolic complication, various strategies for thrombolysis were applied, such as mechanical thrombolysis and intra-arterial or intravenous aggrastat or heparin infusion during or after the procedure.

Immediately after the procedure, a complete neurological examination was performed on all patients by a vascular neurosurgeon. Furthermore, all patients underwent a non-enhanced brain computed tomography (CT) scan to evaluate possible hemorrhagic complications. Unless the thromboembolic complication occurred or a stent was used, further antiplatelet or anticoagulant medications were not administered.
The indications for long-term antiplatelet therapy of acetylsalicylic acid and/or clopidogrel were as follows: formation of a thrombus at the end of the coil or thromboembolic events, stent-assisted coiling, and coil protrusion into the parent artery.

\section{Clinical and angiographic follow-ups}

The immediate and follow-up angiographic results were analyzed. Occlusion was classified as follows: "complete" when no contrast filling of the aneurysmal sac and neck was observed, "near-complete" when contrast filling of the aneurysmal neck was slow, or "partial" when any degree of contrast filling was observed within the aneurysmal sac. The clinical results were assessed upon discharge from the hospital or at the last visit using the modified Rankin scale (mRS) score as follows: 0 , no symptoms at all; 1 , no significant disability; 2 , slight disability; 3 , moderate disability; 4, moderately severe disability; 5, severe disability; and 6, death. A poor clinical outcome was defined as an mRS score of 3 to 6 . Complications were defined as all adverse events related to the procedure, which were studied retrospectively using medical and operative reports. Periprocedural rebleeding (PPR) included both IPR and ERB. IPR was defined as clinically and angiographically evident rupture during the procedure. ERB was defined as expanding hemorrhage with worsening of the patients' condition within 30 days after coiling; diagnosis was confirmed using CT when it showed an increased amount of hemorrhage compared with immediate postprocedural CT.

\section{RESULTS}

The procedural complications and treatment results are summarized in Table 2 .

Immediate angiographic results and complications

All of the aneurysms were successfully treated with coil embolization. The 21 aneurysms were treated using a simple technique. The 14 remaining aneurysms required adjunctive techniques: balloon-assisted $(n=7)$ 
and stent-assisted $(\mathrm{n}=7)$ coiling (Fig. 1). Immediate post-procedural angiograms showed complete occlusion in 25 patients $(71.4 \%)$, near-complete occlusion in $5(14.3 \%)$, and partial occlusion in 5 (14.3\%).

Symptomatic thromboembolic complications developed in only one patient $(0.7 \%)$ during the procedure. In this patient with an RTA at the left distal middle cerebral artery, occlusion of the inferior M2 segment occurred due to thrombus formation at the arterial origin, which resulted in relevant infarction with right hemiparesis. IPR occurred from two RTAs (5.7\%). IPR was diagnosed on the basis of the results of the angiographic visualization of contrast material extravasation in both cases. The coil was observed partially outside the aneurysm with a sudden rise in arte-

Table 2. Procedural complications and treatment results

\begin{tabular}{|c|c|}
\hline $\begin{array}{l}\text { Used technique, } \mathrm{n}(\%) \\
\text { Simple coiling } \\
\text { Stent assisted coiling } \\
\text { Balloon assisted coiling }\end{array}$ & $\begin{array}{rr}21 & (60) \\
7 & (20) \\
7 & (20) \\
\end{array}$ \\
\hline $\begin{array}{l}\text { Complications, n (\%) } \\
\text { Thromboembolism } \\
\text { Intraprocedural rupture } \\
\text { Early rebleeding } \\
\text { latrogenic CCF }\end{array}$ & $\begin{array}{ll}1 & (2.9) \\
2 & (5.7) \\
2 & (5.7) \\
1 & (2.9)\end{array}$ \\
\hline $\begin{array}{l}\text { Immediate angiographic } \\
\text { Complete } \\
\text { Near complete } \\
\text { Partial }\end{array}$ & $\begin{aligned} 25 & (71.4) \\
5 & (14.3 .) \\
5 & (14.3)\end{aligned}$ \\
\hline $\begin{array}{l}\text { Follow-up angiographic } r \\
\text { Stable occlusion } \\
\text { Minor recanalization } \\
\text { Major recanalization }\end{array}$ & $\begin{aligned} 20 & (90.9) \\
1 & (4.5) \\
1 & (4.5)\end{aligned}$ \\
\hline $\begin{array}{l}\text { mRS, n (\%) } \\
0-2 \\
3-6\end{array}$ & $\begin{aligned} 31 & (88.6) \\
4 & (11.4)\end{aligned}$ \\
\hline
\end{tabular}

rial blood pressure in both cases. Prompt heparin reversal with protamine sulfate and additional coiling could prevent the newly developed neurologic deficit in both patients. We also experienced two cases (5.7\%) of ERB after EVT of the RTAs. The mean delay time between coiling and ERB was 12.5 days (range, 12-13). These two aneurysms were located at the anterior communicating artery (Fig. 2) and distal anterior cerebral artery, respectively. In both cases, regrowth and rerupture of the coiled RTAs were confirmed on an immediate angiography, and additional coil embolization was performed. ERB did not have a long-term negative effect on the two patients. No neurologic deficit developed in the four patients with PPR. Conversely, there was one case of carotid-cavernous fistula, in which iatrogenic internal carotid artery dissection was performed; this complication was solved by immediate stenting.

\section{Clinical status at discharge or during follow-up}

Only one patient had symptomatic vasospasm $(2.9 \%)$, and no negative long-term effects were observed. Two patients $(5.7 \%)$ had shunt-dependent hydrocephalus. The clinical results were assessed upon discharge from the hospital or at the last follow-up visit using the mRS score. At the end of the observational period, 31 of the 35 patients $(88.6 \%)$ were independent, with an mRS score of $0-2$; the other four patients $(11.4 \%)$ were dependent, with an mRS score of 3-6. One of these four patients had an mRS score of 6 (owing to traumatic brain hemorrhage after

Table 3. Literature review of endovascular treatment of RTAs

\begin{tabular}{|c|c|c|c|c|c|c|c|c|c|c|c|}
\hline Author & $\begin{array}{c}\text { Total } \\
\text { ruptured }\end{array}$ & $\begin{array}{l}\text { Total } \\
\text { coiled }\end{array}$ & $\begin{array}{l}\text { Mean } \\
\text { size }\end{array}$ & $\begin{array}{l}\text { Complete } \\
\text { occlusion }\end{array}$ & $\begin{array}{l}\text { Remnant/ } \\
\text { partial } \\
\text { occlusion }\end{array}$ & $\begin{array}{l}\text { Periproce- } \\
\text { dural } \\
\text { rebleeding }\end{array}$ & $\begin{array}{l}\text { Sympto- } \\
\text { matic } \\
\text { thrombosis }\end{array}$ & $\begin{array}{l}\text { Major } \\
\text { recanali- } \\
\text { zation }\end{array}$ & $\begin{array}{c}\text { Patient } \\
\text { with } \\
\text { favorable } \\
\text { outcome }\end{array}$ & $\begin{array}{c}\text { Patient } \\
\text { with } \\
\text { poor } \\
\text { outcome }\end{array}$ & $\begin{array}{l}\text { Angiog- } \\
\text { raphic } \\
\text { FU (MO) }\end{array}$ \\
\hline Wu & 32 & 32 & 2.28 & 13 & 19 & 0 & 0 & 0 & 28 & 4 & 9.3 \\
\hline Zhao & 17 & 17 & 2.26 & 10 & 7 & 0 & 1 & 0 & 16 & 1 & 12.50 \\
\hline Hong & 51 & 40 & 2.55 & 28 & 12 & 2 & 1 & 1 & 40 & 0 & 13.75 \\
\hline Tsutsumi & 19 & 19 & 2.82 & 16 & 3 & 0 & 0 & 0 & 15 & 4 & 41.81 \\
\hline Chen & 10 & 9 & 2.55 & 9 & 0 & 0 & 0 & 0 & 8 & 1 & 5.33 \\
\hline Suzuki & 21 & 21 & 2.64 & 20 & 0 & 1 & 0 & 0 & 21 & 0 & 25.0 \\
\hline Total (percent) & 150 & 138 & & 96 (69.6) & 41 (29.7) & $3(2.2)$ & $2(1.4)$ & 1 (0.7) & $128(92.8)$ & $10(7.2)$ & \\
\hline Present (percent) & 35 & 35 & 2.53 & 25 (71.4) & $10(28.6)$ & $4(11.4)$ & 1 (2.9) & 1 (2.9) & 31 (88.6) & $4(11.4)$ & 15.6 \\
\hline
\end{tabular}

$\mathrm{RTA}=$ ruptured tiny aneurysm $(\leq 3 \mathrm{~mm}) ; \mathrm{FU}=$ follow-up; $\mathrm{MO}=$ months 
falling down during hospital stay); two had an mRS score of 5 (owing to poor preoperative status and old age); and one had an mRS score of 3 (owing to old age). The 34 surviving patients were followed up for 6-80 months (mean, 17.2 months). No neurologic dete-
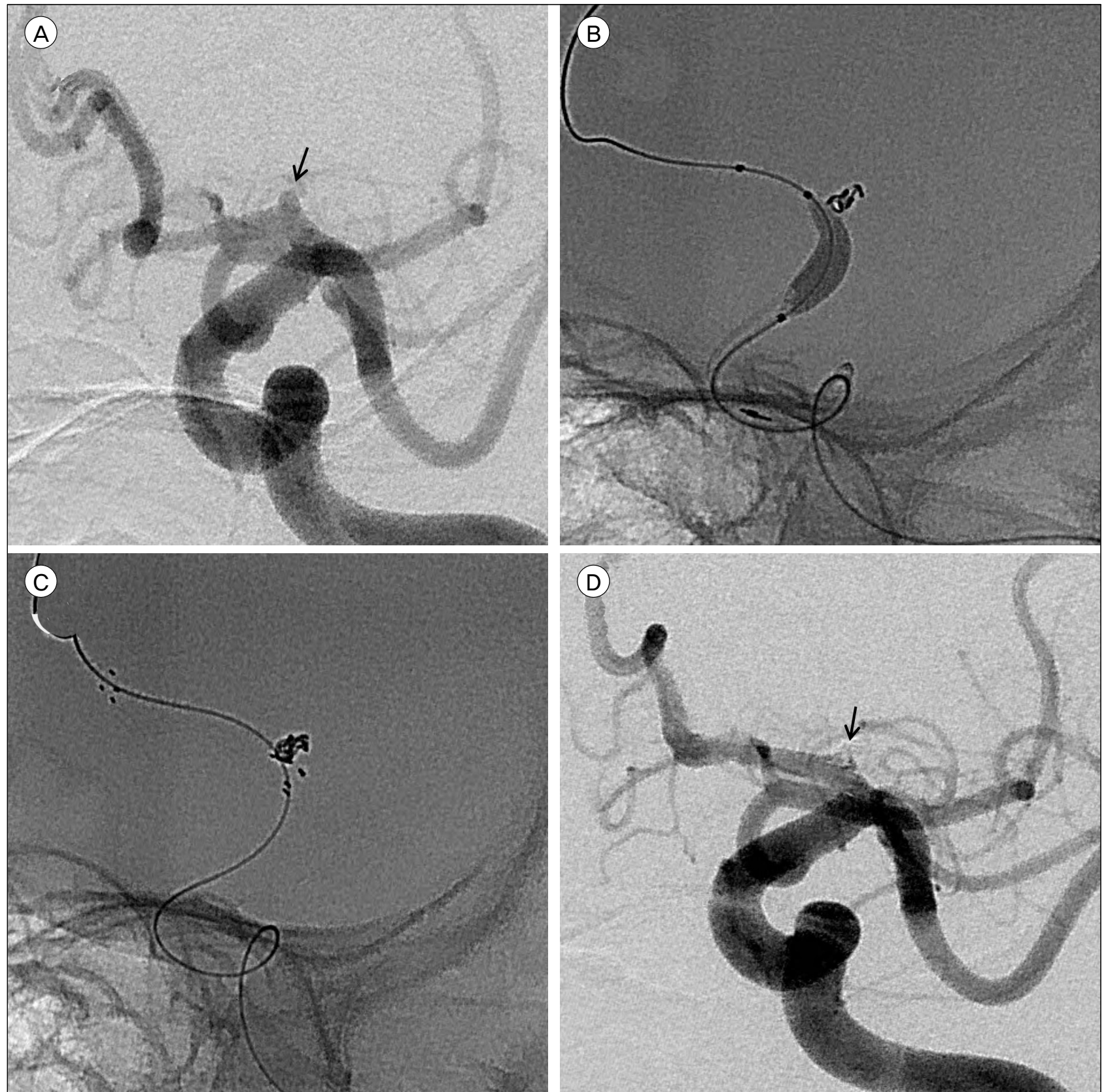

Fig. 1. Images of a 73-year-old woman with a ruptured aneurysm of the left A1 segment. (A) Diagnostic angiography demonstrates a 2.8-mm saccular aneurysm (arrow) arising at the left proximal A1. (B) Sceptor C balloon is positioned across the aneurysmal neck to stabilize the microcatheter and prevent intraprocedural rupture at the same time. (C) Owing to the broad-neck configuration of this aneurysm, the coil mass was supported by a Neuroform 3 stent at the end of the procedure. (D) Subtracted image acquired immediately after coiling demonstrate complete occlusion of the aneurysm (arrow) without compromising the parent artery. 
postoperatively (mean, 15.6 months). Based on the follow-up images obtained, all 16 initially occluded RTAs remained completely occluded. Two of the three RTAs initially showing near-complete occlusion remained stable at follow-up. The remaining RTA achieved minor recanalization owing to coil compac- tion; repeat follow-up angiography at 18 months showed that the condition of the patient was stable. Consequently, the patient declined additional therapy. Two of the three RTAs initially showing partial occlusion seemed to be stable at follow-up. The remaining RTA achieved major recanalization; recoiling was per-
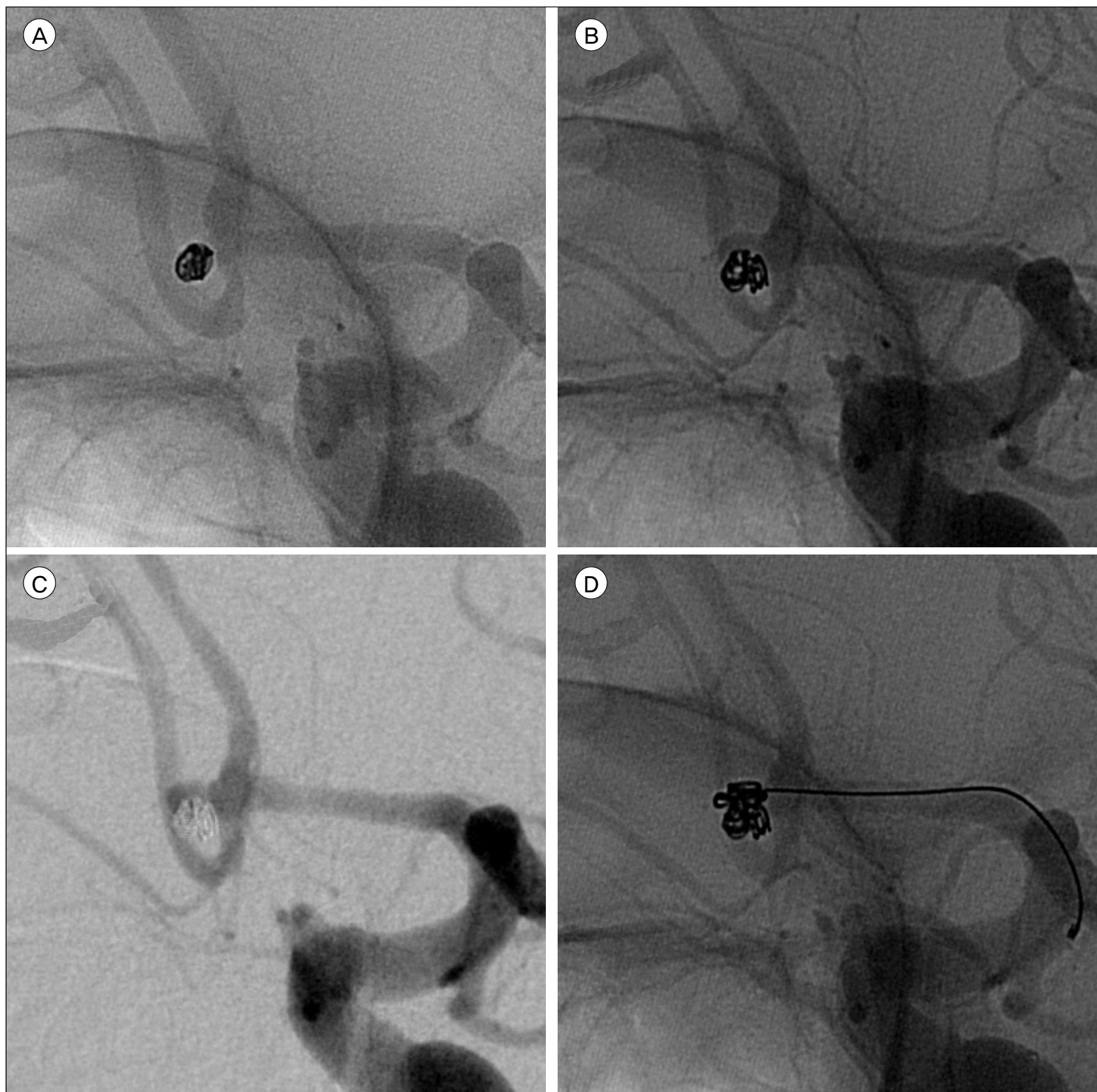

Fig. 2. Images showing a $2.5-\mathrm{mm}$ ruptured aneurysm of the left anterior communicating artery in a 34-year-old man. (A) Unsubtracted image acquired immediately after simple coiling demonstrating complete aneurysm occlusion. Unsubtracted (B) and subtracted (C) images acquired immediately after rebleeding two weeks later show reopening by enlargement of the aneurysm. (D) Additional coiling was performed. 
formed in the patient at 14 months postoperatively, and complete occlusion was achieved (Fig. 3). Thus, the overall stable occlusion rate was $90.9 \%(20 / 22)$, and the recanalization rate was $9.1 \%(2 / 22)$.
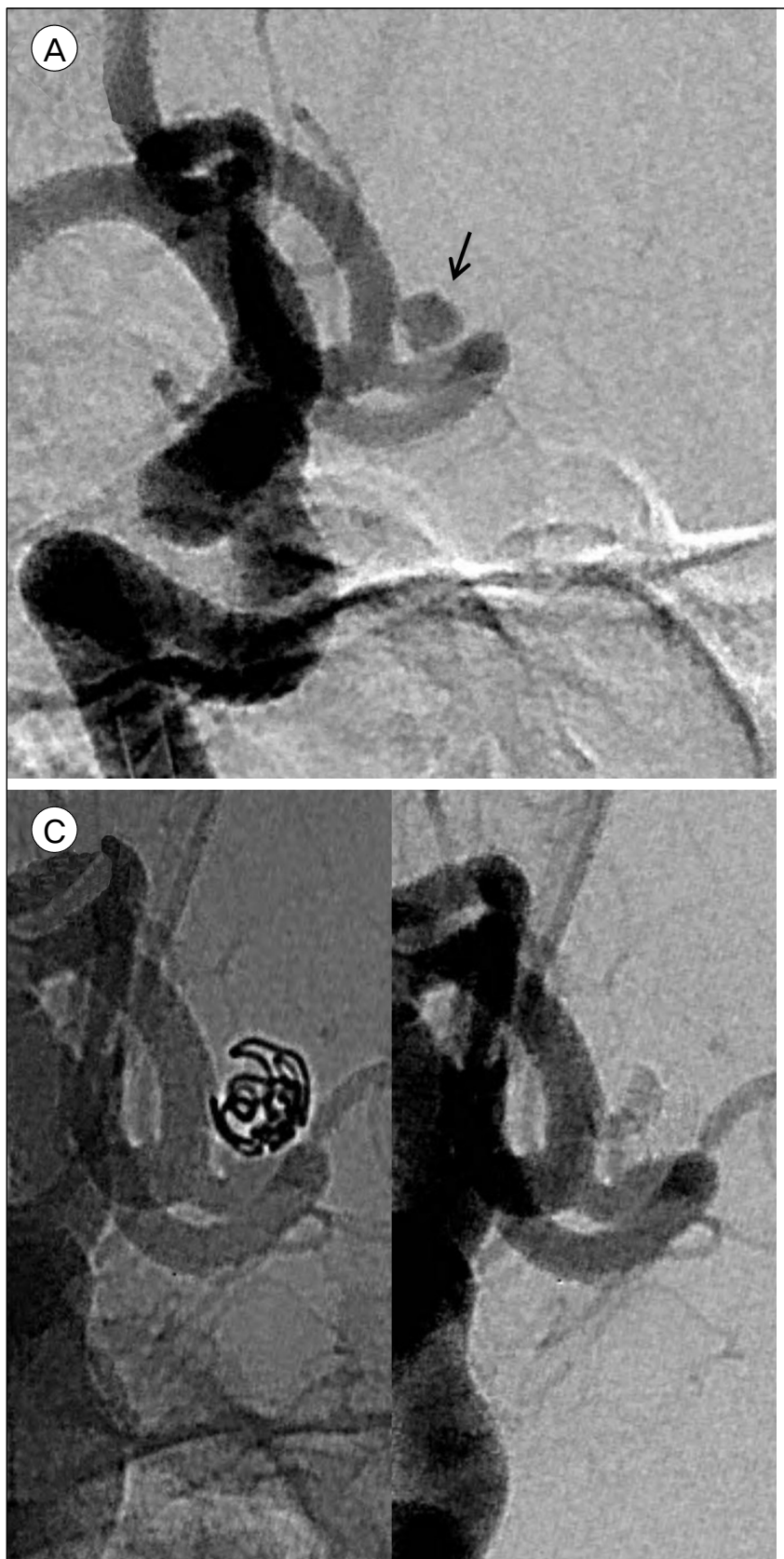

Fig. 3. Recanalization requiring re-treatment. (A) A 49-year-old woman with subarachnoid hemorrhage found to have a distal $A$ aneurysm (arrow) projecting to the left and measuring $2.9 \mathrm{~mm}$ in maximum diameter. (B) Unsubtracted image ac $\neg$ quired immediately after simple coiling demonstrating complete aneurysm occlusion. (C) Follow-up angiogram at 14 months shows reopening by enlargement of the aneurysm in diameter and more loosened coil frame. (D) Final image acquired immediately after additional coiling demonstrates complete occlusion of the aneurysm. 
and complex shape, difficulty in maintaining microcatheter stability, difficulty in achieving complete coil packing, and higher risk of IPR. The introduction of new microcatheters and microguidewires with improved trackability, pushability, torque, and novel hydrophilic coatings has facilitated navigation into RTAs. Furthermore, the availabilities of various soft coils may have contributed to the higher success rate of small aneurysm coiling without IPR.

In this series of 35 endovascularly treated RTAs, immediate post-procedural angiograms showed complete occlusion in $71.4 \%$ of the patients, near-complete occlusion in $14.3 \%$, and partial occlusion in $14.3 \%$. The procedure-related complications included two cases of IPR $(5.7 \%)$, one case of thromboembolic event $(2.9 \%)$, and two cases of ERB, which needed recoiling $(5.7 \%)$. At the end of the follow-up, $88.6 \%$ of the patients showed favorable outcomes (mRS score, 0-2). Follow-up conventional angiography (mean, 468 days) showed stable occlusion in $90.9 \%$, minor recanalization in $4.5 \%$, and major recanalization, which required recoiling, in $4.5 \%$. In our series, an anterior choroidal aneurysm has a much higher ratio than a posterior communicating aneurysm (17.1\% vs 5.7\%). Because an anterior choroidal aneurysm tends to rupture easily even in relatively small sizes, and there is our policy of surgical treatment for a fetal-type posterior communicating aneurysm. In addition, we have recently favored the remodeling techniques using a balloon or stent or multiple catheters to achieve higher postoperative occlusion rates, and to prevent the kick-back movement of the microcatheter, especially in RTA cases.

Only a few studies have compared between the outcomes of coiling of RTAs and ruptured larger aneurysms. We attempted to determine the risk and effectiveness of coiling of RTAs by comparing them with those of coiling of larger ones reported in previous studies. In the International Subarachnoid Aneurysm Trial (ISAT), which is the largest prospective randomized study on endovascular and neu- rosurgical treatments of ruptured intracranial aneurysms of all sizes, follow-up angiography (mean, 12 months) showed complete occlusion in $66 \%$ of aneurysms, neck remnant in $26 \%$, and partial occlusion in $8 \% .{ }^{13)}$ In that series, favorable clinical outcomes were achieved in $73.9 \%$ of the patients. Further, the rate of IPR was $1.9 \%$. Except IPR that occurred more frequently in our series, the results of our study are similar to those of the ISAT. Van Rooji et al. compared between the clinical outcomes after coiling of 196 very small aneurysms (size, $\leq 3 \mathrm{~mm}$ ) in 187 patients and those of 1099 larger aneurysms in 1006 patients. ${ }^{19)}$ They found that $76 \%(149 / 196)$ of the very small aneurysms were ruptured, and $94.9 \%$ were completely occluded; further, $87.2 \%$ of the patients showed favorable outcomes at follow-up. IPR occurred in 15 of the 196 (7.7\%) very small aneurysms and in 36 of the 1099 (3.6\%) larger aneurysms. They concluded that coiling of aneurysms sized $\leq 3 \mathrm{~mm}$ was technically feasible with a lower complication rate comparable with that of larger aneurysms. However, the rate of IPR was much higher in the very small aneurysms than in the larger aneurysms. As detailed above, several studies on coiling of very small aneurysms reported a high rate of IPR but concluded that coiling of such aneurysms was technically feasible with a low complication rate and good clinical outcomes. ${ }^{12) 19)}$ In other reports, IPR did not actually increase the overall morbidity and mortality rates. ${ }^{419)}$ Our research findings support their hypothesis. In our series, the two patients who experienced IPR showed favorable neurological outcomes (mRS score, 0-2) and could function independently.

We summarized the reported studies in which more than 10 patients with RTAs were treated with EVT in Table 3.5)17)18)21)23) These studies included 150 aneurysms, of which 138 were coiled. Similar to our results, 96 of the $138(69.6 \%)$ coiled aneurysms were completely occluded, while 41 (29.7\%) were partially occluded or had a small remnant. There were three cases of IPR and one case of symptomatic thrombosis 
during the procedure. We compared the results of our study and those of the previous studies we reviewed in Table 3. The other results are similar to ours, except for PPR. Our series showed a rate of PPR of $11.4 \%$, while the reviewed studies revealed only a total rate of $2.2 \%$. Most of the previous studies reviewed did not report ERB. However, we think that the importance of ERB in coiling of RTAs cannot be overemphasized. Prior studies on ERB after coiling have reported rupture rates of $1.4 \%$ to $2.6 \%{ }^{9}{ }^{910) 16}$ ) Incomplete embolization, adjacent hematoma, small aneurysms, and post-procedural anticoagulation have been reported to be associated with ERB after coiling. The Cerebral Aneurysm Rerupture After Treatment study reported that the risk of post-treatment rebleeding was closely associated with the degree of aneurysm occlusion. ${ }^{10)}$ However, we experienced two cases of ERB (5.7\%), despite both aneurysms being completely embolized during the procedure. The presence of adjacent hematoma is a strong, independent risk factor of ERB, and a thrombosed pseudoaneurysm and hematoma could cause early reopening and rebleeding. ${ }^{16)}$ In our series, both cases of ERB had no adjacent hematoma. Conversely, Cho et al., who reported on early recurrent hemorrhage after coil embolization in ruptured intracranial aneurysms, hypothesized another possibility that rebleeding with intracranial hemorrhage ( $\mathrm{ICH}$ ) may be caused by delayed hemorrhage or propagation of the initial ICH owing to vulnerability of the parenchyma adjacent to the $\mathrm{ICH}$, rather than by rebleeding of the coiled aneurysm. ${ }^{6}$ ERB after coiling of a ruptured aneurysm and intraprocedural rupture are major concerns because the associated mortality rates are high. When an RTA is accompanied by adjacent hematoma, decisions regarding EVT should be taken only after carefully considering the possibility of PPR. Therefore, it may be better to consider surgical clipping of an RTA with adjacent hematoma as the first option to prevent PPR. Yamaki et al. conducted a meta-analysis on the outcomes of EVT of very small aneurysms (size, $\leq 3$ $\mathrm{mm}){ }^{22)}$ They reported a complete occlusion rate of $88 \%$ after coil embolization of RTAs. Among their patients diagnosed with RTAs treated with EVT, 74\% showed favorable neurological outcomes. The rates of PPR, symptomatic thromboembolism, recanalization, and retreatment were $9 \%, 4 \%, 9 \%$, and $7 \%$, respectively. They reported a high rate of PPR similar to ours. In retrospect, two cases of ERB and one case of IPR occurred in the early period of this series at our institution. It is assumed that the lack of experience of aneurysm coiling and undeveloped coil technology at that time might have partially contributed to the higher rate of PPR. It is believed that small aneurysms are more prone to IPR because there is less room for manipulation of endovascular devices. ${ }^{15)}$ Because stiffness is inversely proportional to the length of the coil segment, the stiffness of the initial coil segment would be higher in smaller aneurysms than in larger aneurysms; therefore, the risk of rupture would be higher in the former than in the latter. ${ }^{2)}$

This study is limited by its retrospective design, patient selection bias, small cohort, and the fact that it was conducted at a single institution. Further, direct comparison with microsurgical clip reconstruction of ruptured tiny saccular aneurysms is difficult given the very small number of published series. However, our findings suggest that EVT of RTAs appears to be a valid treatment strategy given suitable levels of institutional and operator expertise. Moreover, appropriate patient selection for endovascular versus surgical intervention could lead to better outcomes in patients with RTAs.

\section{CONCLUSION}

Our experiences show that EVT for RTAs is both feasible and effective. However, PPR was found to occur more often $(11.4 \%)$ than what is generally suspected. Development of coil technology allows a favorable outcome in EVT of RTAs. 


\section{REFERENCES}

1. Anokwute M, Braca J, Bohnstedt B, DeNardo A, Scott J, Cohen-Gadol A, et al. Endovascular treatment of ruptured tiny $(3 \mathrm{~mm})$ intracranial aneurysms in the setting of subarachnoid hemorrhage: A case series of 20 patients and literature review. J Clin Neurosci. 2017 Jun;40:52-6.

2. Baumgart F. Stiffness-an unknown world of mechanical science? Injury. 2000;31(2):14-23.

3. Brinjikji W, Lanzino G, Cloft H, Rabinstein A, Kallmes D. Endovascular treatment of very small $(3 \mathrm{~mm}$ or smaller) intracranial aneurysms: report of a consecutive series and a meta-analysis. Stroke. 2010 Jan;41(1):116-21.

4. Brisman J, Niimi Y, Song J, Berenstein A. Aneurysmal rupture during coiling: Low incidence and good outcomes at a single large volume center. Neurosurgery. 2005 Dec;57(6):1103-8.

5. Chen Z, Feng H, Tang W, Liu Z, Miao H, Zhu G. Endovascular treatment of very small intracranial aneurysms. Surg Neurol. 2008 Jul;70(1):30-5; discussion 5.

6. Cho Y, Lee J, Seo J, Kang H, Kim J, Kwon O, et al. Early recurrent hemorrhage after coil embolization in ruptured intracranial aneurysms. Neuroradiology. 2012 Jul;54(7):719-26.

7. Gao B, Li T, Li L, Xu G, Yang B. Tiny cerebral aneurysms can be treated safely and effectively with Low-Profile Visualized Intraluminal Support stent-assisted coiling or coiling alone. World Neurosurgery. 2018 May;113:e426-e30.

8. Hong B, Yang P, Zhao R, Huang Q, Xu Y, Yang Z, et al. Endovascular treatment of ruptured tiny intracranial aneurysms. J Clin Neurosci. 2011 May;18(5):655-60.

9. Jartti P, Isokangas J, Karttunen A, Jartti A, Haapea M, Koskelainen $\mathrm{T}$, et al. Early rebleeding after coiling of ruptured intracranial aneurysms. Acta Radiol. 2010 Nov;51(9):1043-9.

10. Johnston $S$, Dowd C, Higashida R, Lawton $M$, Duckwiler G, Gress D, et al. Predictors of rehemorrhage after treatment of ruptured intracranial aneurysms: the Cerebral Aneurysm Rerupture After Treatment (CARAT) study. Stroke. 2008 Jan;39(1):120-5.

11. Lum C, Narayanam S, Silva L, Shankar J, Bussiere M, Dos Santos M, et al. Outcome in small aneurysms $(<4$ $\mathrm{mm}$ ) treated by endovascular coiling. J Neurointervention Sur. 2012;4(3):196-8.

12. Mitchell P, Muthusamy S, Dowling R, Yan B. Does small aneurysm size predict intraoperative rupture during coiling in ruptured and unruptured aneurysms? J
Stroke Cerebrovasc Dis. 2013;22(8):1298-303.

13. Molyneux A, Kerr R, Group ISATC. International Subarachnoid Aneurysm Trial (ISAT) of neurosurgical clipping versus endovascular coiling in 2143 patients with ruptured intracranial aneurysms: a randomized trial. J Stroke Cerebrovasc Dis. 2002;11(6):304-14.

14. Nguyen T, Raymond J, Guilbert F, Roy D, Berube M, Mahmoud M, et al. Association of endovascular therapy of very small ruptured aneurysms with higher rates of procedure-related rupture. J Neurosurg. 2008 Jun;108(6):1088-92.

15. Sluzewski M, Bosch J, van Rooij W, Nijssen P, Wijnalda D. Rupture of intracranial aneurysms during treatment with Guglielmi detachable coils: incidence, outcome, and risk factors. J Neurosurg. 2001 Feb;94(2):238-40.

16. Sluzewski M, van Rooij W. Early rebleeding after coiling of ruptured cerebral aneurysms: incidence, morbidity, and risk factors. AJNR Am J Neuroradiol. 2005 Aug;26(7):1739-43.

17. Suzuki S, Kurata A, Ohmonmo T, Sagiuchi T, Niki J, Yamada $M$, et al. Endovascular surgery for very small ruptured intracranial aneurysms. J Neurosurg. 2006 Nov;105(5):777-80.

18. Tsutsumi M, Aikawa H, Onizuka M, Kodama T, Nii K, Matsubara S, et al. Endovascular treatment of tiny ruptured anterior communicating artery aneurysms. Neuroradiology. 2008 Jun;50(6):509-15.

19. Van Rooij W, Keeren G, Peluso J, Sluzewski M. Clinical and angiographic results of coiling of 196 very small $(\leq$ $3 \mathrm{~mm}$ ) intracranial aneurysms. AJNR Am J Neuroradiol. 2009;30(4):835-9.

20. van Rooij W, Sluzewski M, Beute G, Nijssen P. Procedural complications of coiling of ruptured intracranial aneurysms: incidence and risk factors in a consecutive series of 681 patients. AJNR Am J Neuroradiol. 2006 Aug;27(7):1498-501.

21. Wu P, Ocak P, Wang D, Ocak U, Xu S, Li Y, et al. Endovascular Treatment of Ruptured Tiny Intracranial Aneurysms with Low-Profile Visualized Intraluminal Support Device. J Stroke Cerebrovasc Dis. 2019 Feb;28(2):330-7.

22. Yamaki V, Brinjikji W, Murad M, Lanzino G. Endovascular treatment of very small intracranial aneurysms: meta-analysis. AJNR Am J Neuroradiol. 2016;37(5):862-7.

23. Zhao R, Shen J, Huang Q, Nie J, Xu Y, Hong B, et al. Endovascular treatment of ruptured tiny, wide-necked posterior communicating artery aneurysms using a modified stent-assisted coiling technique. J Clin Neurosci. 2013 Oct;20(10):1377-81. 